DOI: $10.14451 / 2.127 .31$

\title{
РОЛЬ UNFAIR CONTRACT TERMS ACT В РЕГУЛИРОВАНИИ ОТНОШЕНИЙ С УЧАСТИЕМ ПОТРЕБИТЕЛЕЙ В АНГЛИИ
}

\author{
(c) 2019 Тутаев Джабраил Вахитович \\ аспирант кафедры гражданского права, процесса и международного частного права \\ Российский университет дружбы народов \\ 117198, г. Москва, ул. Миклухо-Маклая, д. 10/2
}

В рамках настоящего исследования автором анализируется Unfair Contract Terms Act в качестве основного нормативного акта, обеспечивающего права и законные интересы потребителей. Автором исследуются цели принятия данного закона, регулируемые им отношения и средства правовой защиты, устанавливаемые законом в случае нарушения его требований в части создания недобросовестных и несправедливых условий одной из сторон.

Ключевые слова: ответственность, договор, несправедливые условия, недобросовестные условия, потребитель.

В Англии в 1977 году был принят Закон «О недобросовестных договорных условиях» [1], вступивший в силу 1 февраля 1978 года. Несмотря на то, что в названии закона фигурирует только «договорные» условия, его положения распространяются на недоговорные уведомления и извещения, имеющие положения об освобождении стороны договора от ответственности за деликт.

Отметим, что названный закон не предоставляет судам права по собственному усмотрению исключать из положений договора условия, будь они несправедливы или неразумно обременительны. В основном, положения закона используются по отношению к условиям, которые «исключают или ограничивают ответственность». Закон «О недобросовестных договорных условиях», далее по тексту - Закон, не имеет положений, которые бы так, или иначе, влияли на основания наступления ответственности. Учитывая, что у судов нет полномочий собственной волей изменять существо договора или отдельные его условия, то к основному вопросу, рассматриваемому судом на основании этого закона, следует отнести вопрос о возложении или невозложении ответственности на сторону, которая добивается применения недобросовестного или несправедливого условия, закрепленного в договоре. Конечно, суду также следует установить, является ли условие об освобождении от ответственности договорным и, если да, то в какой мере оно относится, с учетом толкования положений договора, к ограничению или исключению ответственности определенной стороны договора. Кроме того, при принятии решения, суд будет учитывать то, что нормы статутного права, закрепленные в указанном законе, будут иметь преобладающее значение, чем, например, постулаты доктрины нарушения основного условия договора.

Следует отметить, что Закон регламентирует не любые правоотношения, оформленные в виде договора. Так, указанный Закон не регулирует правоотношения, вытекающие из:

- договора страхования;

- коммерческого чартера;

- договоров морской перевозки грузов;

- договоров, опосредующих передачу прав и полномочий в отношении земельных участков и некоторые другие.

Учитывая, что положения Закона не стремятся охватить неограниченный круг договорных правоотношений, а сосредоточиваются только на тех, которые прямо не исключены соответствующей нормой, по содержанию он (Закон) получился весьма небольшим. При этом, авторы Закона, видимо намеренно, постарались избежать возможных лакун и сформулировали взаимно перекрывающие друг друга нормы, что по мнению некоторых английских исследователей привело к наличию спорных ситуаций.

Итак, к основным целям Закона о недобросовестных договорных условиях 1977 года следует отнести:

1. Регламентацию договорных положений о видах договорных условий, ограничивающих или освобождающих от ответственности сторону договора. Принимая во внимание некоторые исключения (ст. ст. 3(2) (В), 4), положения Закона 
регулируют исключительно договорные условия, направленные на исключение или ограничение конкретных видов ответственности. Особо отметим, положения Закона также включают в себя, согласно ст. 13, условия:

- подчиняющие положения об ответственности либо ее принудительном применении ограничительным или же намеренно обусловленным обстоятельствам;

- исключающие или минимизирующие определенное право стороны договора или ее средство правовой защиты в отношении ответственности либо причиняющие ущерб лицу, ставший следствием стремления лица добиться реализации такого права или средства правовой защиты;

- удаляющие или минимизирующие нормы о средствах и доказательствах нарушения [1].

Определенные нормы Закона (ст.ст. 2, 5-7), имеющие отсылочный характер к положениям закона, исключающими или минимизирующими обязательство или обязанность стороны как способа, запрещающего ограничение или исключение ответственности. Косвенная цель Закона также заключается в том, чтобы не только исключить возможность злоупотребить договорными условиями в части исключения ответственности, но и также создать условия для невозможности применения косвенных условий договора, обходными путями исключающими или уменьшающими ответственность стороны договора. К числу таких косвенных условий договора можно отнести те, которые, например, определяют предельный срок требования замены или ремонта товара. Достаточно часто в английской правоприменительной практике встречаются случаи, когда в договорах одна из сторон указывает, что наличие определенного документа, подтверждающего квалификацию исполнителя будет являться для другой стороны безусловным доказательством качественного выполнения работ или оказания услуг. На контроле со стороны Закона будут находиться также и те условия договора, которые одна из сторон определила как «сторона не дает каких-либо гарантий или обязательств, прямо выраженных или подразумеваемых, в отношении поставленных товаров», поскольку они заведомо вызывают вопросы относительно их добросовестности.

2. Противодействие исключению одной из сторон договора собственной коммерческой ответственности. Закон стремится устранить свои- ми положениями действия договорных условий, исключающих или ограничивающих условие об «ответственности за нарушение обязательств или обязанностей, имеющих место» [1]:

- в отношение вещей или предметов, уже существующих или тех, что будут созданы лицом в процессе своей коммерческой деятельности;

- в отношении владения и пользования помещениями для достижения владельцем коммерческих целей.

Надо здесь отметить, что в деле Town Investments, Ltd. v. Department of the Environment [2], термин «коммерческая деятельность» было признано «этимологическим хамелеоном». Дело в том, что на практике бывает очень сложно определить, что такое «коммерческая деятельность», за которую может быть наложена «коммерческая ответственность. В частности, не всегда можно разобрать, что представляет из себя деятельность учебного заведения, которое набирает на платное обучение учеников. Так, в Законе сказано, что коммерческая деятельность не всегда может осуществляться с целью получения прибыли. Поэтому этот вопрос в рамках Закона остается до конца неисследованным и рассматривается в зависимости от конкретной ситуации.

3. Защиту от недобросовестных и несправедливых условий договора потребителей как наиболее уязвимой стороны. В отдельных положениях Закона можно обнаружить достаточно четкое разграничение между ситуацией, когда стороной договора является потребитель, и ситуацией, когда стороной договора является иное лицо с точки зрения Закона. Сущность такого разграничения заключается в том, что с точки зрения Закона наибольшей защитой должен пользоваться именно потребитель, в сравнении, например с коммерсантом. Для того, чтобы Законом лицо, заключающее договор, относилось к потребителю, необходимо соблюдение следующих условия, предусмотренных ст. 12(1) (a), (b):

- лицо не должно заключать такой договор в процессе осуществления предпринимательской деятельности или демонстрировать, что осуществляет ее;

- контрагент такой стороны должен осуществлять именно коммерческую деятельность и в этой связи заключать договор [1].

В отдельных случаях необходимо соблюдение также еще одного условия. Так, в случаях, когда по договору необходимо передать имущество, 
например, договор купли-продажи, в том числе в кредит, договор аренды и др., должно быть соблюдено еще одно условие: товары, предназначенные для передачи по договору, должны быть из той категории, которая в повседневной жизни предназначена именно для потребителя, а не для осуществления коммерческой деятельности (ст. 12(1) (c). В том случае, если возникла спорная ситуация, бремя доказывания того, что одной из сторон договора является не потребитель, лежит на контрагенте, стремящемся использовать условие об освобождении от ответственности (ст. 12(3) [1].

4. Минимизацию возможности ограничить ответственность за небрежность. Статья 2 Закона прямо указывает на то, что стороны договора не имеют право ограничить свою коммерческую ответственность за небрежность. Более того, что сторона договора не имеет права ссылаться на соответствующее условие договора как на основание освобождения от ответственности за смерть человека или же причиненный ущерб здоровью вследствие небрежности. Это положение закона имеет абсолютно императивный характер.

Сторона договора, осуществляющая коммерческую деятельность в отношении иных потерь или причиненных контрагенту убытков, также не может исключать или минимизировать условиями договора свою ответственность. К исключению можно отнести случаи, когда ответственность должна быть «разумной» (ст. 2(2), (3).

Положение ст. 5 Закона также носит совершенно императивный характер в отношении запрета на ограничение или исключение ответственности изготовителя или продавца при установлении «гарантии» на изготавливаемые или продаваемые изделия. К ст. 5 может быть отнесено только одно условие: такие товары должны считаться повседневно реализуемыми для личного пользования, а возможный ущерб, ими причиняемый, причиняться тогда, когда потребитель использует этот товар для личных нужд [1].

5. Для предоставления гарантий возмещения ущерба или вреда потребителям. В тех случаях, когда лицо заключает договор как потребитель, в его договорные обязанности не может включаться обязанность гарантировать своему контрагенту возместить вред третьему лицу, осуществляющему коммерческую деятельность, в случае небрежности или нарушения договора.
Исключение составляют случаи, когда такое условие отвечает требованиям разумности.

6. Защиты потребителей от несправедливых или недобросовестных условий при реализации товаров в кредит или при заключении договоров купли-продажи. Так, в частности, ст. 6 Закона определяет пределы возможности продавца минимизировать или исключать свою ответственность в случае нарушения условий договоров купли-продажи, подразумеваемых в силу ст.ст.12, 13, 14, 15 Закона о купле-продаже товаров от 1893 г. Абсолютным императивом, запрещающим минимизацию или исключение ответственности продавца за нарушения в отношение титула товара (ст. 12 Закона о купле-продаже товаров) обладает ст. 6 Закона «О недобросовестных договорных условиях». Совершенно такой же по юридической силе императив ст. 6 Закона распространяет на нарушение положения ст. 13-15 закона о купле-продаже товаров 1893 г.: в отношении условий о качестве товаров, пригодных для продажи или пригодности товара для продажи по описанию или образцу - при том, однако, условии, если контрагентом продавца выступает исключительно потребитель. В том же случае, если продавец заключает договор не с потребителем, а с иным лицом, такая ответственность продавца может быть ограничена или вовсе исключена при условии соблюдения требования о разумности (ст. 6(3).

Еще одним аспектом ст. 6 Закона является наличествующий в нем запрет как в абсолютной форме, так и на условиях альтернативности, на минимизацию или исключение ответственности за нарушение продавцом товаров положений о подразумеваемых условиях договоров купли-продажи в кредит, содержащихся в Законе о передаче имущества 1973 года.

7. Регулирования условий договоров о передаче имущества. Так, ст. 7 Закона «О недобросовестных договорных условиях» содержит положения о договорных условиях, минимизирующих или исключающих предпринимательскую ответственность за нарушения подразумеваемых договорных обязательств, в которых «право владения или собственности на товары переходит в соответствии с договором или во исполнение договора» (в число таких договоров не включаются договоры купли-продажи, договоры продажи в кредит либо обмена приобретенных или полученных купонов на реальные товары). К числу таких договоров относят до- 
говоры аренды, договоры обмена, разумеется, договоры строительного подряда или договор инженерного подряда. Как показывает английская практика заключения и исполнения таких договоров, содержащиеся в них подразумеваемые условия, как правило, являются неточными либо же вовсе неопределенными сторонами, что позволяет их трактовать в соответствии с духом договора и обстоятельствами, при которых он был заключен. В тех же случаях, когда в тексте договора подразумеваются обязательства стороны предоставить соответствующий описанию или образцу товар, с соответствующим качеством и пригодностью к использованию по назначению, Законом императивно запрещается минимизация или исключение ответственности продавца, заключившего договор исключительно с потребителем. (ст. 7(2)). Если же такой договор был заключен не с потребителем, а с лицом, выступающем в ином качестве, то для продавца ответственность может быть смягчена или совсем исключена, при том, однако, условии, что такое решение будет отвечать требованию разумности (ст. 7(3)). Если же договор включает в себя положения, исключающие или минимизирующие ответственность продавца за нарушение договорных обязательств в отношении титула либо же добросовестного спокойного владения приобретенным товаром, то они тоже должны соответствовать условию о разумности (ст. 7(4)) [1].

8. Определения меры договорной ответственности сторон. В соответствии с положением ст. 3 Закона, судом могут быть проанализированы условия и основания наступления договорной ответственности на предмет их непротиворечия положениям статутного права. Положения ст. 3 Закона распространяются не только на уже упомянутые нами договоры, предусмотренные ст.ст. 6 и 7 Закона, но и также на договоры купли-продажи, продажи товаров в кредит, а также к договорам, предусматривающим передачу имущества. Положения ст. 3 Закона могут быть применены практически ко всем видам договоров, кроме тех, которые исключаются положениями закона:

- договоры о поездке в выходные дни;

- договоры об услугах химчистки;

- договоры бытового подряда;

- договоры на оказание услуг по стоянке автомобилей с предоставлением места в гараже;

- договоры бытового хранения и некоторые другие.

В тоже время, необходимо помнить, что положения ст. 3 указанного Закона используются в том случае, когда при заключении договора:

1) одна сторона является потребителем;

2) договор заключается в простой письменной форме в качестве договора присоединения, условия которого определены стороной-предпринимателем;

3) сторона-предприниматель в таком договоре несет предпринимательскую ответственность за нарушение договора или его неисполнение.

Выше мы упомянули, что судам разрешается определять, соответствуют или не противоречат ли условия договора нормам статутного права. Это полномочие суда определено нормой ст. 3(2) Закона. Так вот, судебный контроль за положениями договоров может выражаться в следующем: «В отношении потребителя или лица, заключающего договор на условиях, предложенных коммерсантом в типовых формах, другая сторона не имеет права, отсылая к определенным положениям договора:

- исключить или смягчить ли собственную ответственность за нарушение в случае, если она сама нарушает договор;

- при утверждении коммерсантом, являющимся стороной в таком договоре, что они имеют право:

А) осуществить исполнение такого договора существенно отличным способом от того, что контрагент должен был разумно ожидать;

Б) вовсе не осуществлять исполнение, за исключением случаев, при которых условие договора может считаться разумным.

Если прочитать формулировки последних пунктов, то вполне можно увидеть, что, на первый взгляд, они представляют собой обоснование поведения сторон при отсутствии события нарушения договора. При этом один из контрагентов считает для себя возможным, учитывая имеющееся в договоре условие, осуществить исполнение своих договорных обязанностей существенно различающихся с тем, что ее контрагент мог бы ожидать. Еще один вариантом может быть то, что сторона в части своего исполнения договора либо произвела его не в полном объеме, либо не произвела вообще. Например, лицо приобретает туристический продукт, согласно которому туроператор обязуется обеспечить его отдых в установленном месте в отеле уста- 
новленной звездности. Однако, туроператор, в договоре предусматривает право изменить по своему усмотрению не только место, но и звездность отеля или же вовсе отказать лицу в поездке без объяснения причин.

Если бы речь шла о коммерческом договоре, то такое право туроператора вполне могло бы именоваться форс-мажорными обстоятельствами. Однако, если в договоре стороной выступает потребитель, то английская судебная практика с огромной долей вероятности сочтет поведение туроператора неразумным и возложит на него ответственность.

9. Разумность в договорных отношениях между сторонами. Определенное ограничение принципа свободы договора, внесенное Законом в части минимизации или полного исключения ответственности (ст.ст. 2(1), 5, 6(1) (2), 7(2)), дополняется также требованием Закона о том, чтобы условия договора, заключаемого сторонами отвечали критерию «разумности» (ст.ст. 2(2), 3(2), 4, 6(3), 7(3) (4)). На практике это требование означает, что при возникновении споров из условий договора, к которым, в соответствии с Законом, должен применяться критерий «разумности», суд обязан будет установить, является ли условие договора справедливым и относимым к существу этого договора, чтобы находиться в теле договора «с учетом обстоятельств, которые были или разумно должны были быть известными или предусматриваться сторонами при заключении договора» [1]. Поэтому ясно, что решающим является момент заключения договора, а не момент, когда возникает ответственность [3].

Критерий «разумности» договорного условия не обусловливается степенью тяжести или условием наступления ущерба для стороны, не принимая во внимание случаи, когда наступление такого ущерба было предусмотрено в условиях договора. Кроме того, английская практика исходит из того, что определенные обстоятельства, о которых знал только один контрагент, имеющий намерение воспользоваться условием об исключении или смягчении ответственности, не нужно принимать во внимание при возникновении спора, поскольку такие обстоятельства не были известны и разумно не могли быть известны контрагенту по договору до момента его подписания.

Закон определяет критерии, которыми следует руководствоваться при определении «разумности» обстоятельств, требующих учета при рассмотрении споров из договоров:

- «сила позиций сторон на переговорах по отношению друг к другу, учитывая, помимо прочего, возможные альтернативные способы, которыми можно было бы удовлетворить требование потребителя (customer);

- приобрел ли потребитель выгоду от согласия с условием договора, либо же, подписывая договор, у потребителя существовала возможность заключить такой же договор с иным продавцом, не обременяющим договор таким условием;

- знал ли или должен был разумно покупатель знать о существовании и степени влияния такого условия, принимая во внимание, помимо прочего, обычаи делового оборота, торговые обыкновения либо предшествующие деловые отношения между сторонами;

- когда ситуация исключает либо ограничивает всякую имеющую отношение к спору ответственность при нарушении какого-то условия, было ли разумным перед заключением договора полагать, что исполнение такого условия будет выполнимым;

- были ли продавцом учтены пожелания потребителя, если да, то в какой части, по переработке или предоставлению нового товара» [1].

В этой связи известный английский исследователь В. Ансон отмечает: «строго говоря, эти указания применимы к проверке разумности только в отношении исключения или ограничения ответственности за нарушение подразумеваемых обязательств в договорах купли-продажи, продажи в кредит и в договорах передачи имущества. Однако, нет сомнений в том, что они будут применяться по аналогии (в тех случаях, когда они имеют отношение к делу), к другим ситуациям, в которых возникает вопрос о разумности условия в соответствии с положениями Закона. Тем не менее, даже когда эти указания могут быть прямо применены, они не являются исчерпывающими; от суда требуется учет, «в частности», названных обстоятельств, но он может принять во внимание и любые другие относящиеся к делу обстоятельства» [4].

Позиция В.Ансона представляется верной, поскольку законом невозможно охватить все условия, при которых могут быть заключены договоры. Не случайно, далее В.Ансон отмечает: «если положение договора ограничивает ответственность определенной денежной суммой (например, при условии, что такая общая 
ответственность продавца за потери и убытки вследствие недостатков товаров ограничивается 20000 фунтов стерлингов и возникает вопрос о том, отвечает ли это положение требованию разумности, следует учитывать также:

- средства, которыми продавец может располагать для покрытия ответственности, если она наступит;

- какую он имел возможность для того, чтобы прибегнуть к страхованию. Это положение было включено для защиты мелких предприятий, и, возможно, также лиц, занимающихся профессиональной деятельностью, которые могут не располагать средствами для несения неограниченной ответственности, если она наступит, и которые могут быть не в состоянии застраховать такую ответственность. В подобных случаях вполне разумным могло бы быть установление денежного предела ответственности» [4].

Итак, подводя итог исследования английского права на предмет несправедливых условий договора, можно сказать следующее. Несомнен- но, важную роль в направлении последовательного ограничения применения сторонами условий, минимизирующих или исключающих ответственность за нарушение договора, сыграл Закон «О недобросовестных договорных условиях» 1977 года. Пожалуй, наиболее заметным действие Закона обнаружилось в потребительской сфере: само принятие этого закона, снабженного многочисленными положениями, направленными на защиту прав потребителей, говорит о признании на государственном уровне неравенство сторон при заключении договоров с профессиональными участниками рынка - предпринимателями. Законом «О недобросовестных договорных условиях» 1977 года были значительно расширен перечень средств правовой защиты, предоставляемых потребителю, в число которых вошли:

- средства защиты, относящиеся к договорам купли-продажи в кредит;

- введена ответственность за небрежность;

- расширено понятие договорной ответственности.

\section{Библиографический список}

1. Закон о несправедливых условиях договора 1977 г. (Unfair Contract Terms Act). https://www.adgm.com/ media/30840/33-Unfair-Contract-Terms-Act-1977.pdf

2. Town Investments, Ltd. v. Department of the Environment, 1977, http://www.unece.org/fileadmin/DAM/env/pp/ compliance/C2011-64/Communication/Annex25_ch5_DeSmith-GroundsofJudicialReview.pdf

3. Ст. 49(4) Закона Англии «О Верховном суде» 1925 г. // http://www.wipo.int/wipolex/ru/details.jsp?id=1721

4. Ансон В. Договорное право. Изд-во «Юридическая литература». М.1984. С. 143. 